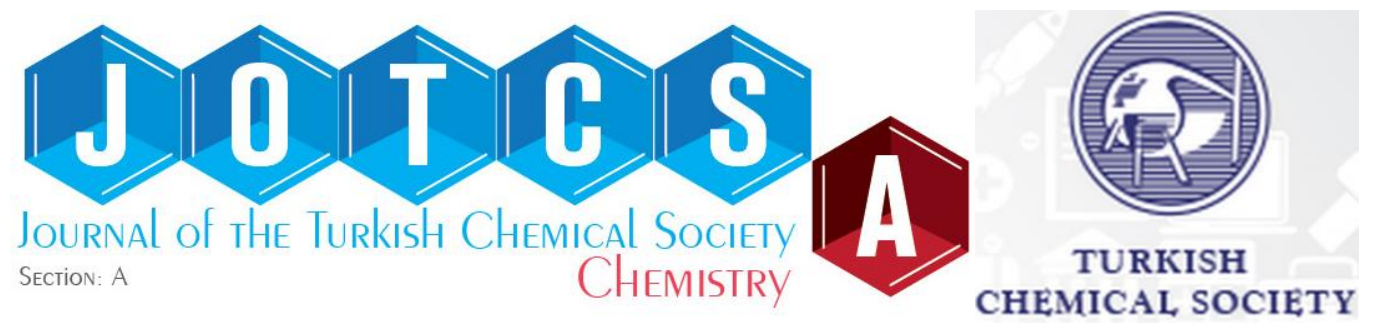

\title{
Combination of Photoinduced ATRP and Click Processes for the Synthesis of Triblock Copolymers
}

\section{Gorkem YILMAZ ${ }^{*}$}

\author{
${ }^{1}$ Istanbul Technical University, Department of Chemistry, Maslak, Istanbul 34469, Turkey
}

\begin{abstract}
ABA type triblock copolymers possessing polystyrene as middle segment and poly $(\varepsilon-$ caprolactone) (PCL) and poly(ethylene glycol) ( $P E G$ ) as side segments were synthesized by combining two photochemical strategies, namely photoinduced atom transfer radical polymerization (ATRP) and click processes. For this purpose, $a, \omega$-diazido functional polystyrene $\left(\mathrm{N}_{3}-\mathrm{PS}-\mathrm{N}_{3}\right)$ was synthesized by photoinduced ATRP using a bifunctional initiator, followed by a simple substitution of the chain end halides. Parallel to this, the alkyne-PCL was synthesized by ring opening polymerization of $\varepsilon$-caprolactone, employing propargyl alcohol as initiator. For the synthesis of alkyne-PEG, industrially available PEG was functionalized by a simple esterification reaction using 5-pentynoic acid. After the syntheses of these alkyne functional polymers as clickable counterparts, they were reacted with $\mathrm{N}_{3}-\mathrm{PS}-\mathrm{N}_{3}$ by photoinduced click reactions to prepare the desired triblock copolymers. All polymers were characterized by NMR, FTIR, and GPC analyses.
\end{abstract}

Keywords: Atom transfer radical polymerization, copper-catalyzed azide-alkyne cycloaddition, photochemistry, block copolymers

Submitted: April 10, 2018. Accepted: April 18, 2018.

Cite this: YIlmaz G. Combination of Photoinduced ATRP and Click Processes for the Synthesis of Triblock Copolymers. JOTCSA. 2018;5(2):727-36.

DOI: $\underline{\text { http://dx.doi.org/10.18596/jotcsa.414060. }}$

*Corresponding author. E-mail: a.gorkemyilmaz@gmail.com. 
Yılmaz G. JOTCSA. 2018; 5(2): 727-736.

RESEARCH ARTICLE

\section{INTRODUCTION}

Development of controlled/living radical polymerization (CLRP) processes has brought a complete breath of fresh air to the synthetic polymer community by providing molecular weight and functional group control over the materials prepared (1-4). Among the most intensively used CLRP techniques, Atom Transfer Radical Polymerization (ATRP) has attracted a great deal of interest, as its applicability to a wide range of monomers and high tolerance to a variety of chemical environments (5-8). In addition, it eventually yields polymers with halogen chain-end functionality, which can be used for further modification processes. Combination of ATRP with highly effective click reactions provides the syntheses of complex macromolecular architectures including telechelic polymers (5), block (9), graft $(10,11)$, and star copolymers $(12,13)$, which cannot be synthesized by a single polymerization mechanism. The most favored click reactions by the synthetic polymer scientists are undoubtedly the Diels-Alder (14) and copper-catalyzed azide-alkyne cycloaddition $(\operatorname{CuAAC})(14,15)$ reactions that can be realized with almost quantitative efficiencies. Specifically, CuAAC reactions, which occur between an alkyne and azido functionality, is the most intensively investigated click reaction due to the possibility of performing these reactions under milder conditions in comparison to Diels-Alder reactions.

Both ATRP and CuAAC require low oxidation state copper $(\mathrm{Cu}(\mathrm{I}))$ complexes as catalysts (Scheme 1).

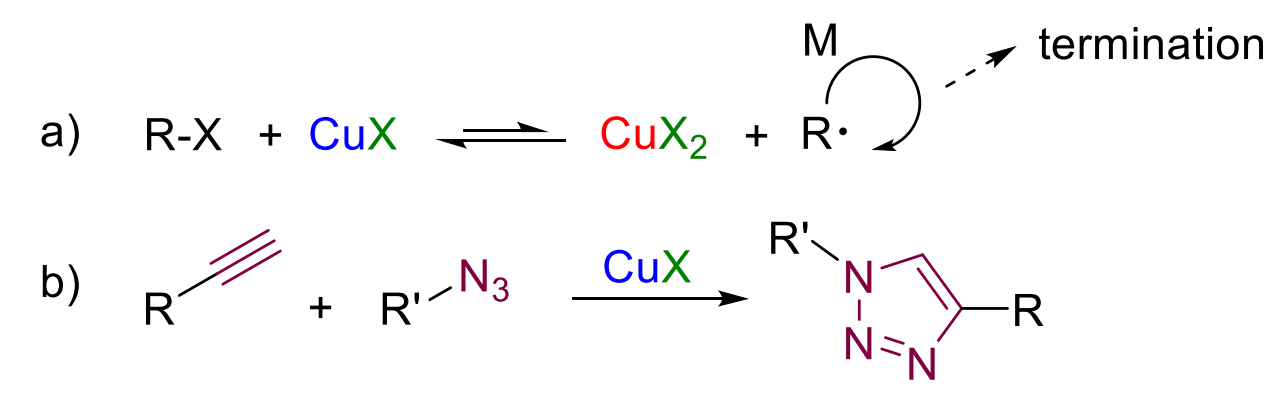

Scheme 1. Conventional ATRP and CuAAC.

Therefore, a major drawback surfaces as $\mathrm{Cu}(\mathrm{I})$ complexes may undergo oxidation that alter the rates of reactions. Thus, concurrent generation of $\mathrm{Cu}$ (I) catalysts by the reduction of the $\mathrm{Cu}$ (II) complexes was proposed to deal with this problem. This is achievable by using the chemical reduction method, which require phenols, ascorbic acid, and hydrazines as reducing agents (16, 17). Alternatively, photochemical reduction processes can also be utilized by employing radicalic photoinitiators or photosensitizers (18-21).

Photochemical approaches have distinctive advantages in comparison to other strategies as they supply 3D-shape control over the materials prepared and temporal control over the reactions. To take such advantages, photochemical processes were utilized to ATRP techniques and CuAAC 
(Scheme 2).(9, 22-24) Specifically, decomposition of certain photoinitiators yield radicals, which can efficiently reduce $\mathrm{Cu}(\mathrm{II})$ in to $\mathrm{Cu}(\mathrm{I})$ catalysts required.

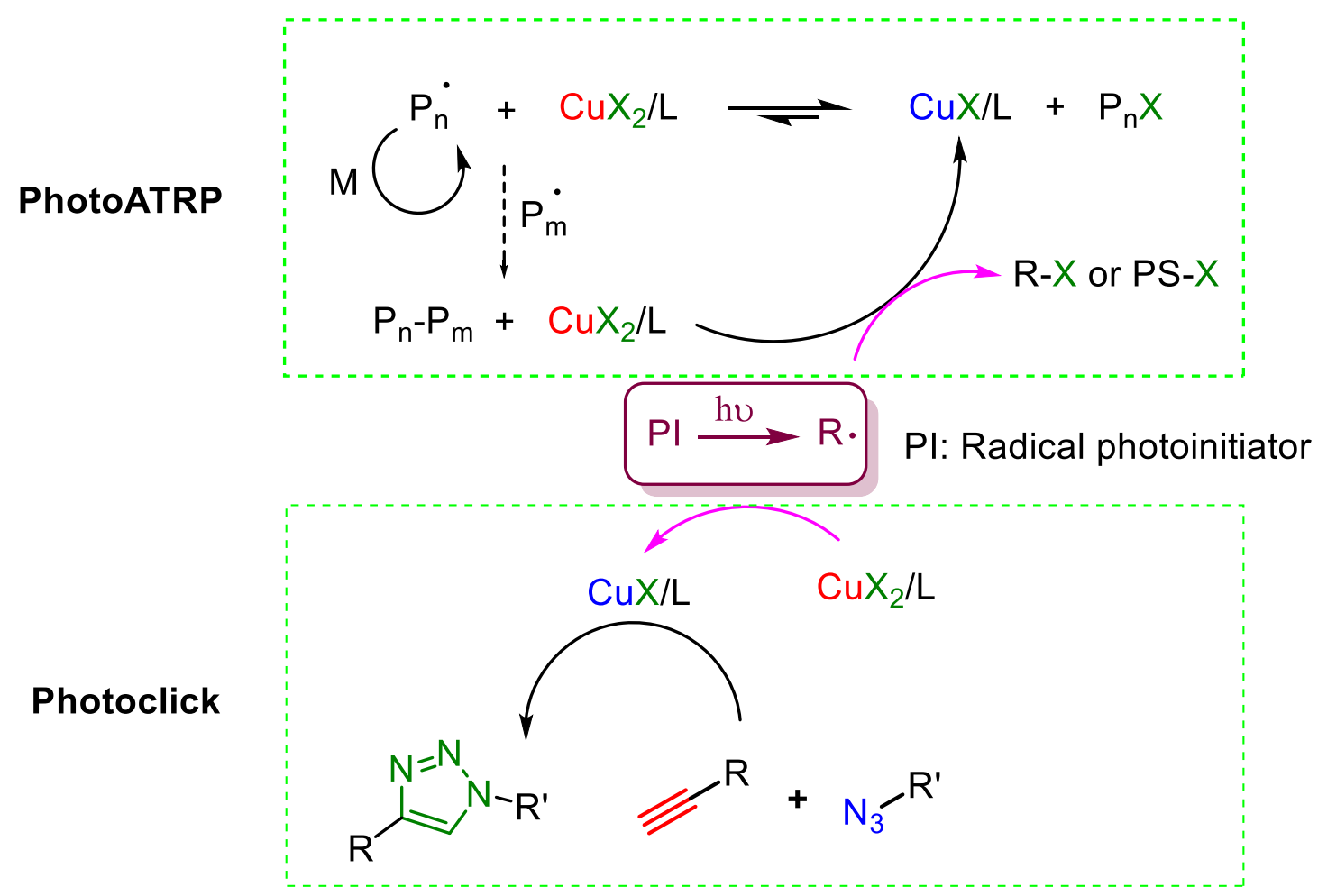

Scheme 2. Photoinduced ATRP and CUAAC reactions.

Herein, a novel strategy for the preparation of triblock copolymers by the combination of two photoinduced processes, namely ATRP and click reactions was described. For this purpose, a bifunctional ATRP initiator was used, which yielded bifunctional polystyrene ( $\mathrm{Br}-\mathrm{PS}-\mathrm{Br}$ ). Subsequently, the halogen functionalities were substituted to azido groups, which will be used for click reactions $\left(\mathrm{N}_{3}-\mathrm{PS}-\mathrm{N}_{3}\right)$. In parallel to this, alkyne functional poly( $\varepsilon$-caprolactone) alkynePCL and poly(ethylene glycol) (alkyne-PEG) were synthesized as clickable counterparts. Finally, these polymers with antagonist groups were clicked under photoinduced reaction conditions to afford the triblock copolymers. The structures were confirmed by spectral analyses and the molecular weight characteristics were analyzed by chromatographic measurements.

\section{EXPERIMENTAL SECTION}

\section{Materials}

a,a'-Dibromo-p-xylene, sodium azide (97\%, Sigma-Aldrich), $N, \quad N, \quad N^{\prime}, \quad N^{\prime \prime}, \quad N^{\prime \prime}-$ pentametyldiethylenetriamine (PMDETA, 99\%, Aldrich), copper(II) bromide (98\%, Acros), tin(II) chloride, poly(ethylene glycol) methyl ether (Me-PEG, $M_{\mathrm{n}} \sim 550 \mathrm{~g} / \mathrm{mol}$, Aldrich), N, N'dicyclohexylcarbodiimide (DCC, 99\%, Aldrich), bis (2, 4, 6-trimethylbenzoyl)phenylphosphine oxide (BAPO) were used as recieved. Styrene ( $99 \%$, Aldrich) and $\varepsilon$-Caprolactone (99\%, Aldrich) were vacuum-distilled prior to use. 
Yılmaz G. JOTCSA. 2018; 5(2): 727-736.

RESEARCH ARTICLE

\section{Characterization}

${ }^{1} \mathrm{H}$ NMR of the polymers were recorded at room temperature using a Bruker AC250 (250.133 $\mathrm{MHz}$ ) instrument. Molecular weight characteristics of the polymers were analyzed by using gel permeation chromatography (GPC) (Agilent 1100 instrument) using polystyrene standards.

\section{Syntheses of Precursor Polymers}

a, $\omega$-Bromo functional polystyrene (Br-PS-Br) $(25)\left(M_{\mathrm{n}, \mathrm{NMR}}=4800, M_{\mathrm{n}, \mathrm{GPC}}=5400 \mathrm{~g} / \mathrm{mol}, M_{\mathrm{w}} / M_{\mathrm{n}}=\right.$ 1.38), a, $\omega$-azido functional polystyrene $\left(\mathrm{N}_{3}-\mathrm{PS}-\mathrm{N}_{3}\right)(24) M_{\mathrm{n}, \mathrm{GPC}}=5600 \mathrm{~g} / \mathrm{mol}, M_{\mathrm{w}} / M_{\mathrm{n}}=1.37$ ), aalkyne functional poly( $\varepsilon$-caprolactone) (Alkyne-PCL) $(26,27)\left(M_{n, N M R}=2100 ; M_{n, G P C}=2600\right.$; $M_{\mathrm{w}} / M_{\mathrm{n}}=1.22$ and $\omega$-alkyne functional poly(ethylene glycol) $\left(M_{\mathrm{n}, \mathrm{GPC}}=690 ; M_{\mathrm{w}} / M_{\mathrm{n}}=1.09\right)$ were prepared according to modified literature procedures.

\section{Photoinduced CuAAC reactions}

A typical photoinduced CUAAC reaction is carried out as follows: to a Schlenk tube equipped with a magnetic stirrer, $\mathrm{N}_{3}-\mathrm{PS}-\mathrm{N}_{3}$ (1.0 eq), alkyne-PCL or alkyne-PEG (1.2 eq), ligand (PMDETA, 0.5 eq) and $\mathrm{CuCl}_{2}(0.5 \mathrm{eq})$ was added and dissolved in dry DMF. The reaction mixture was purged with nitrogen for $5 \mathrm{~min}$ and the tube was sealed, which was then exposed to visible light irradiation $(\lambda=400-500 \mathrm{~nm}$ ) for $24 \mathrm{~h}$. At the end of the irradiation, the reaction mixture was poured into ten-fold excess methanol and the precipitate was filtered off and dried. (PCL- $b$-PS$b$-PCL: (Yield: $91 \%,\left(M_{\mathrm{n}, \mathrm{NMR}}=8150 \mathrm{~g} / \mathrm{mol}, M_{\mathrm{n}, \mathrm{GPC}}=8750 \mathrm{~g} / \mathrm{mol}, M_{\mathrm{w}} / M_{\mathrm{n}}=1.31\right)$; PEG- $b$-PS- $b-\mathrm{PEG}$ : Yield: $94 \%,\left(M_{\mathrm{n}, \mathrm{NMR}}=5690 \mathrm{~g} / \mathrm{mol}, M_{\mathrm{n}, \mathrm{GPC}}=6150 \mathrm{~g} / \mathrm{mol}, M_{\mathrm{w}} / M_{\mathrm{n}}=1.27\right)$.

\section{RESULTS AND DISCUSSION}

For the preparation of triblock copolymers, $\mathrm{N}_{3}-\mathrm{PS}-\mathrm{N}_{3}$ was synthesized as the clickable inner segment by applying photoinduced ATRP, followed by a simple substitution reaction using sodium azide. In parallel to this, alkyne-PCL and alkyne-PEG was synthesized, which were then photochemically clicked with $\mathrm{N}_{3}-\mathrm{PS}-\mathrm{N}_{3}$ to afford the corresponding PCL- $b$-PS- $b$-PCL and PEG- $b$ PS- $b$-PEG triblock copolymers. In both photoinduced steps, bis(acyl)phosphine oxide (BAPO) was used as the photoreducing agent for the generation of $\mathrm{Cu}(\mathrm{I})$ catalyst. The choice of BAPO lies back on the high efficiency of the phosphonyl radicals to reduce $\mathrm{Cu}$ (II) salts as reported previously $(24,28,29)$. The overall process for the synthesis of triblock copolymers is shown in Scheme 3. 


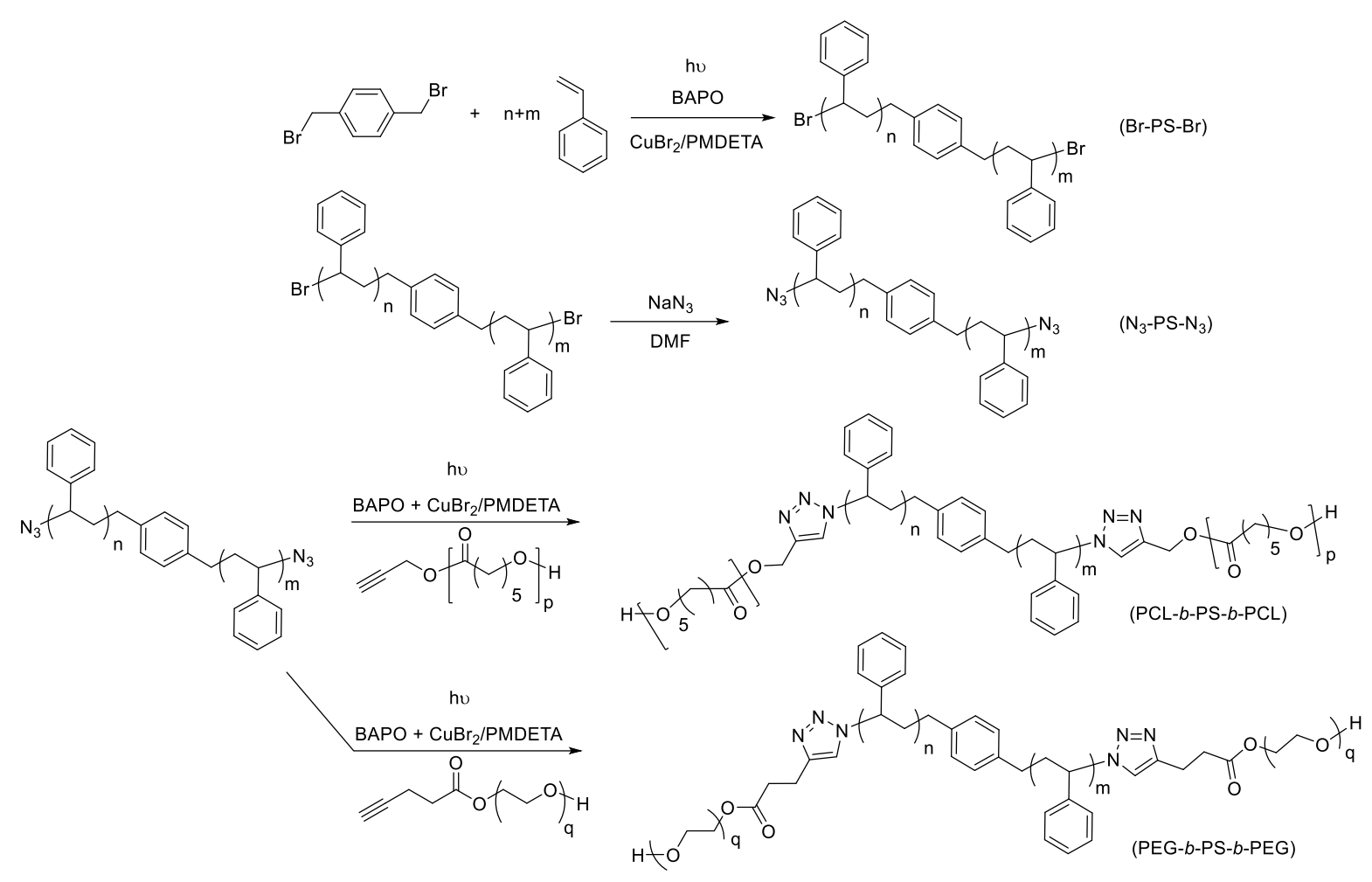

Scheme 3. Syntheses of PCL- $b$-PS- $b$-PCL and PEG- $b$-PS- $b$-PEG by the combination of photoinduced ATRP and CUAAC processes.

The structures of the triblock copolymers were investigated by ${ }^{1} \mathrm{H}$ NMR spectroscopy (Figure 1 ). The ${ }^{1} \mathrm{H}$ NMR spectra of both triblock copolymers show the characteristic protons of the main segments. The triazole proton appeared at 7.9 and $7.6 \mathrm{ppm}$ in the spectra of PCL- $b-\mathrm{PS}-b-\mathrm{PCL}$ and PEG- $b$-PS- $b$-PEG, respectively (peak $a$ in Figure $1(a)$ and (b)), which were used for the calculation of the efficiency of the photoinduced click processes. By comparing the integrated ratios of the triazole peaks with respect to the main PS protons, the click efficiencies were calculated to be $91 \%$ and $94 \%$ (for PCL- $b$-PS- $b$-PCL and PEG- $b$-PS- $b$-PEG, respectively). In addition, the peaks appeared around $5.1 \mathrm{ppm}$ are attributed to the protons adjacent to the triazole ring (peaks shown as $b+c$ in both cases). 


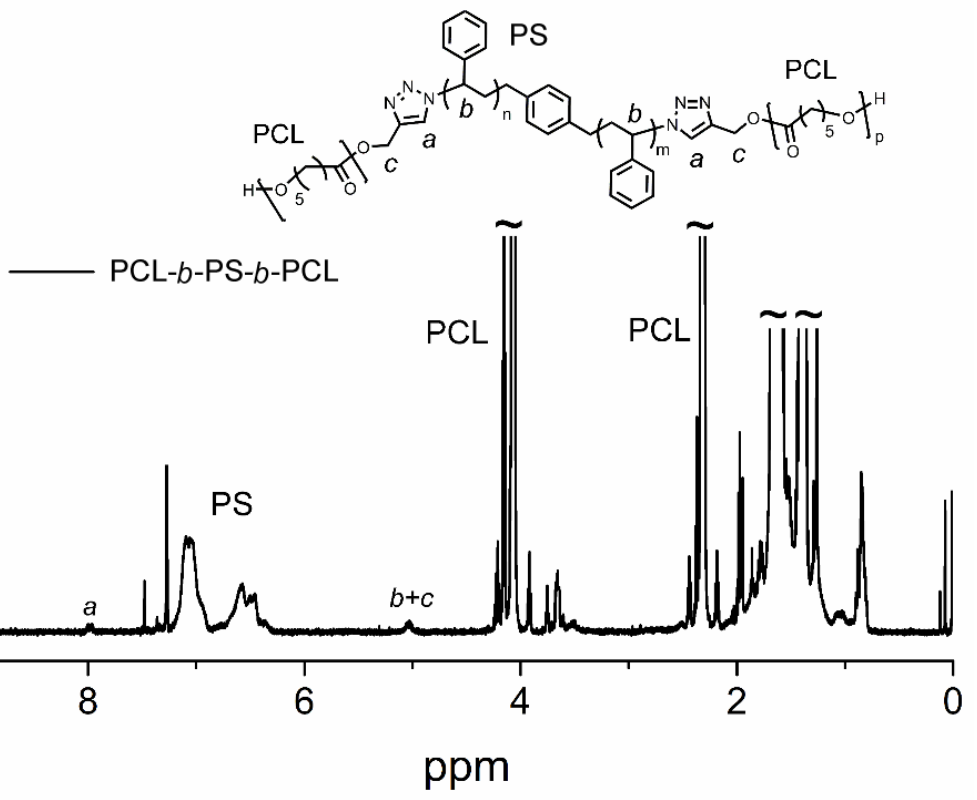

(a)

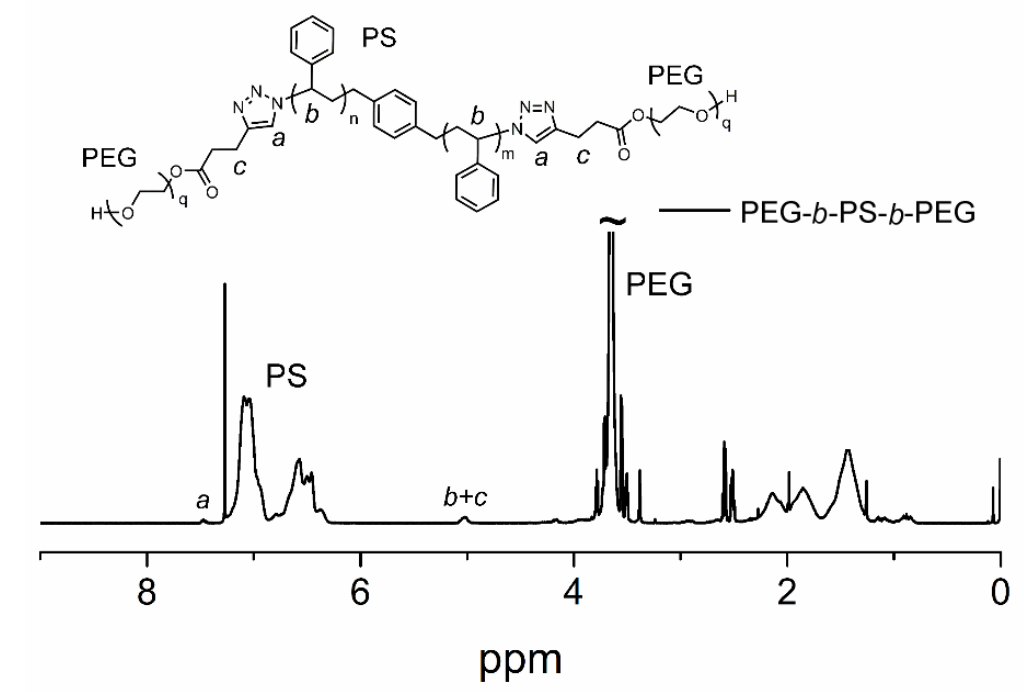

(b)

Figure 1. ${ }^{1} \mathrm{H}$ NMR spectra of PCL- $b$-PS- $b$-PCL (a) and PEG- $b-P S-b-P E G$ (b). Solvent:

$\mathrm{CDCl}_{3}$.

The photoinduced click reactions were also followed by FT-IR analyses (Figure 2). In both figures, the black line above shows the FT-IR spectrum of $\mathrm{N}_{3}-\mathrm{PS}-\mathrm{N}_{3}$, which clearly displays a transition around $2100 \mathrm{~cm}^{-1}$ corresponding to the azide functionality. Clearly, after the triblock copolymer formations, the aforementioned peak disappeared and new stretching peaks around $1730 \mathrm{~cm}^{-1}$ and $1100 \mathrm{~cm}^{-1}$ appeared, which relate to the carbonyl groups of PCL and etheric bonds of PEG segments, correspondingly. 
(a)
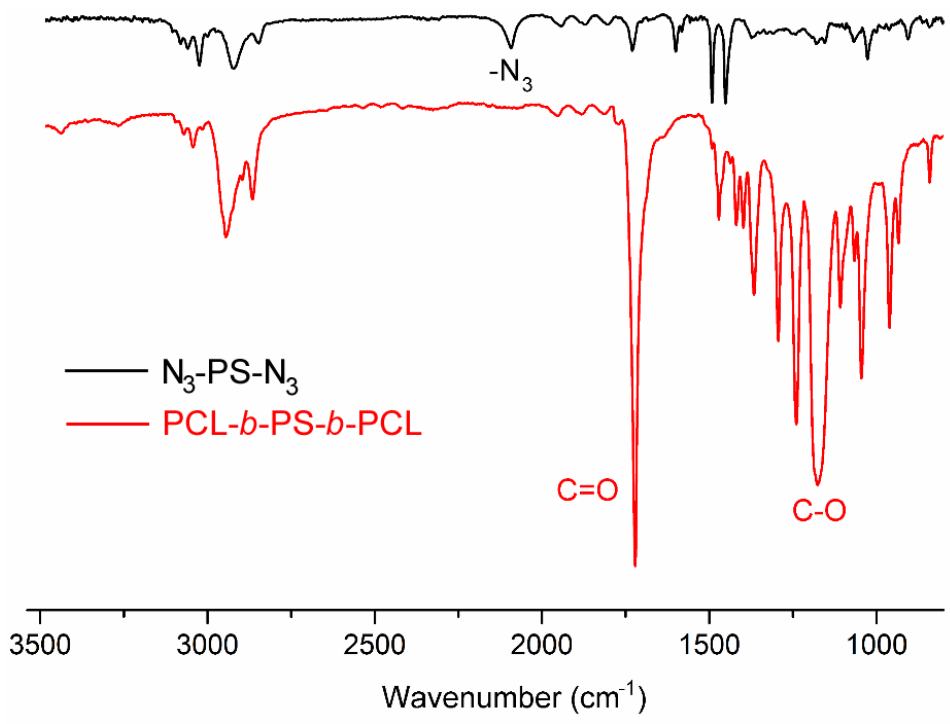

(b)

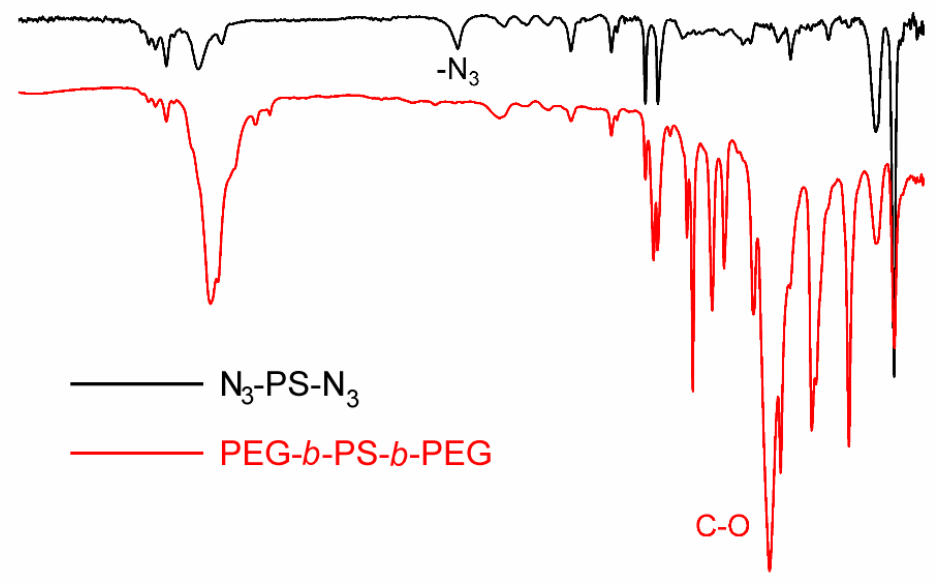

$3500 \quad 3000 \quad 2500 \quad 2000 \quad 1500,1000$

Figure 2. Comparison of the FT-IR spectra of $\mathrm{N}_{3}-\mathrm{PS}-\mathrm{N}_{3}$ with PCL- $b-\mathrm{PS}-b-\mathrm{PCL}(a)$ and PEG- $b$-PS- $b$-PEG.

The success of the photoinduced CUAAC reaction was also proved by GPC analyses. As can be seen from Figure 3, there is a clear shift to the high molecular weight region in both cases with respect to the precursor polymers. The unimodal regime of the chromatograms and the absence of shoulder variations confirm that the triblock copolymer formations are efficiently realized without any side reactions. 
(a)

Alkyne-PCL
$\mathrm{N}_{3}-\mathrm{PS}-\mathrm{N}_{3}$
PCL-b-PS-b-PCL

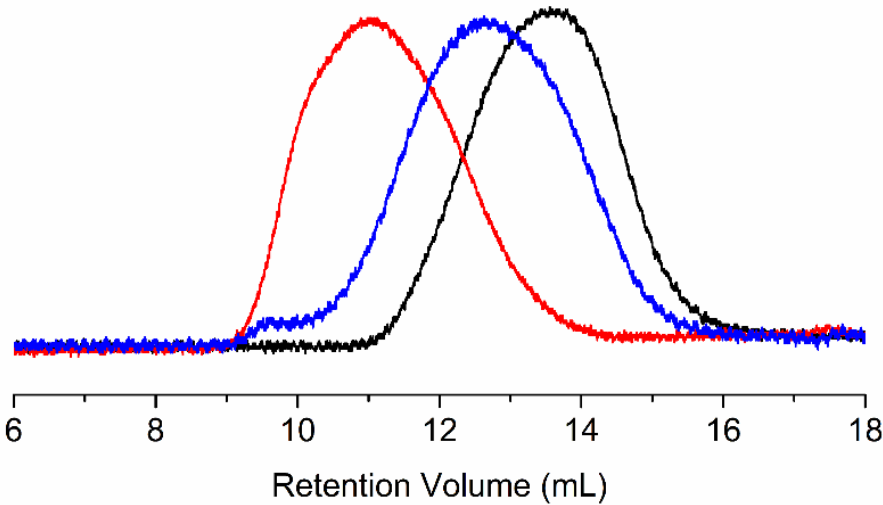

- Alkyne-PEG

$\mathrm{N}_{3}-\mathrm{PS}-\mathrm{N}_{3}$

PEG- $b$-PS- $b$-PEG

(b)

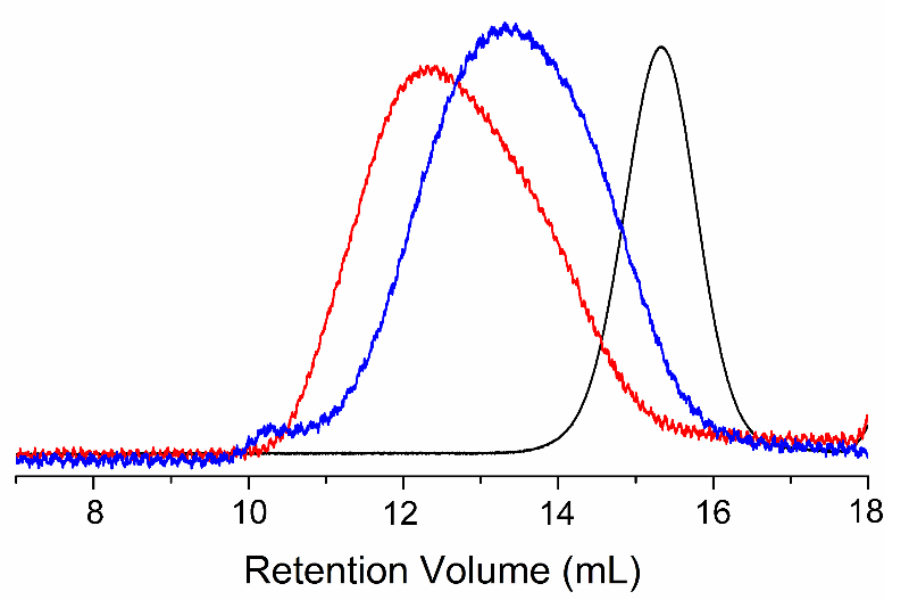

Figure 3. Comparison of the GPC chromatograms of PCL- $b-P S-b-P C L(a)$ and PEG- $b$-PS- $b$-PEG (b) with respect to their precursor polymers.

\section{CONCLUSION}

In conclusion, two photochemical processes, namely photoinduced ATRP and CuAAC, were combined in a sequential fashion for the preparation of triblock copolymers. Given that the antagonist click functionalities are attained at the chain ends of the polymers, the methodology described here was shown to be an efficient and useful strategy for triblock copolymer syntheses. Notably, it provides the preparation of triblock copolymers, which can not be synthesized by a single polymerization technique. Therefore, triblock copolymers with biocompatible segment properties can be synthesized by this strategy as we showed on the case of PCL and PEG. This study is expected to receive interest from the synthetic polymer community and open new pathways for the design and syntheses of various macromolecular architectures. 
Yılmaz G. JOTCSA. 2018; 5(2): 727-736.

\section{REFERENCES}

1. Matyjaszewski K, Xia JH. Atom transfer radical polymerization. Chem Rev. 2001;101(9):2921-90.

2. Chiefari J, Chong YK, Ercole F, Krstina J, Jeffery J, Le TPT, et al. Living free-radical polymerization by reversible addition-fragmentation chain transfer: The RAFT process. Macromolecules. $1998 ; 31(16): 5559-62$.

3. Moad G, Rizzardo E, Thang SH. Living radical polymerization by the RAFT process. Australian Journal of Chemistry. 2005;58(6):379-410.

4. Hawker CJ, Bosman AW, Harth E. New polymer synthesis by nitroxide mediated living radical polymerizations. Chem Rev. 2001;101(12):3661-88.

5. Coessens V, Pintauer T, Matyjaszewski K. Functional polymers by atom transfer radical polymerization. Prog Polym Sci. 2001;26(3):337-77.

6. Matyjaszewski K. Atom Transfer Radical Polymerization (ATRP): Current Status and Future Perspectives. Macromolecules. 2012;45(10):4015-39.

7. Pan X, Tasdelen MA, Laun J, Junkers T, Yagci Y, Matyjaszewski K. Photomediated controlled radical polymerization. Prog Polym Sci. 2016;62:73-125.

8. Wang JS, Matyjaszewski K. CONTROLLED LIVING RADICAL POLYMERIZATION - HALOGEN ATOMTRANSFER RADICAL POLYMERIZATION PROMOTED BY A CU(I)CU(II) REDOX PROCESS. Macromolecules. $1995 ; 28(23): 7901-10$.

9. Yilmaz G, Iskin B, Yagci Y. Photoinduced Copper( I)-Catalyzed Click Chemistry by the Electron Transfer Process Using Polynuclear Aromatic Compounds. Macromol Chem Phys. 2014;215(7):662-8.

10. Pyun J, Kowalewski T, Matyjaszewski K. Synthesis of polymer brushes using atom transfer radical polymerization. Macromol Rapid Commun. 2003;24(18):1043-59.

11. Gacal B, Durmaz H, Tasdelen MA, Hizal G, Tunca U, Yagci Y, et al. Anthracene-maleimide-based Diels-Alder "click chemistry" as a novel route to graft copolymers. Macromolecules. 2006;39(16):5330-6.

12. Iskin B, Yilmaz G, Yagci Y. Synthesis of ABC type miktoarm star copolymers by triple click chemistry. Polym Chem. 2011;2(12):2865-71.

13. Iskin B, Yilmaz G, Yagci Y. ABC Type Miktoarm Star Copolymers Through Combination of Controlled Polymerization Techniques with Thiol-ene and Azide-Alkyne Click Reactions. J Polym Sci, Part A: Polym Chem. 2011;49(11):2417-22.

14. Kolb HC, Finn MG, Sharpless KB. Click chemistry: Diverse chemical function from a few good reactions. Angewandte Chemie-International Edition. 2001;40(11):2004-+.

15. Rostovtsev VV, Green LG, Fokin VV, Sharpless KB. A stepwise Huisgen cycloaddition process: Copper(I)-catalyzed regioselective "ligation" of azides and terminal alkynes. Angewandte ChemieInternational Edition. 2002;41(14):2596-+.

16. Gnanou Y, Hizal G. Effect of phenol and derivatives on atom transfer radical polymerization in the presence of air. J Polym Sci, Part A: Polym Chem. 2004;42(2):351-9.

17. Matyjaszewski K, Jakubowski W, Min K, Tang W, Huang J, Braunecker WA, et al. Diminishing catalyst concentration in atom transfer radical polymerization with reducing agents. Proceedings of the National Academy of Sciences of the United States of America. 2006;103(42):15309-14.

18. Tasdelen MA, Uygun M, Yagci Y. Photoinduced Controlled Radical Polymerization. Macromol Rapid Commun. 2011;32(1):58-62.

19. Konkolewicz D, Schroder K, Buback J, Bernhard S, Matyjaszewski K. Visible Light and Sunlight Photoinduced ATRP with ppm of Cu Catalyst. Acs Macro Lett. 2012;1(10):1219-23. 
20. Tasdelen MA, Uygun M, Yagci Y. Studies on Photoinduced ATRP in the Presence of Photoinitiator. Macromol Chem Phys. 2011;212(18):2036-42.

21. Tasdelen MA, Uygun M, Yagci Y. Photoinduced Controlled Radical Polymerization in Methanol. Macromol Chem Phys. 2010;211(21):2271-5.

22. Shanmugam S, Boyer C. Stereo-, Temporal and Chemical Control through Photoactivation of Living Radical Polymerization: Synthesis of Block and Gradient Copolymers. J Am Chem Soc. 2015;137(31):998899.

23. Shanmugam S, Xu J, Boyer C. Light-Regulated Polymerization under Near-Infrared/Far-Red Irradiation Catalyzed by Bacteriochlorophyll a. Angew Chem Int Ed Engl. 2016;55(3):1036-40.

24. Tasdelen MA, Yilmaz G, Iskin B, Yagci Y. Photoinduced Free Radical Promoted Copper(I)-Catalyzed Click Chemistry for Macromolecular Syntheses. Macromolecules. 2012;45(1):56-61.

25. Wang J-S, Matyjaszewski K. Controlled/"living" radical polymerization. atom transfer radical polymerization in the presence of transition-metal complexes. J Am Chem Soc. 1995;117(20):5614-5.

26. Hoogenboom R, Moore BC, Schubert US. Synthesis of star-shaped poly(?-caprolactone) via 'click' chemistry and 'supramolecular click' chemistry. Chem Commun. 2006(38):4010-2.

27. Jerome C, Lecomte P. Recent advances in the synthesis of aliphatic polyesters by ring-opening polymerization. Advanced drug delivery reviews. 2008;60(9):1056-76.

28. Dursun C, Degirmenci M, Yagci $Y$, Jockusch S, Turro NJ. Free radical promoted cationic polymerization by using bisacylphosphine oxide photoinitiators: substituent effect on the reactivity of phosphinoyl radicals. Polymer. 2003;44(24):7389-96.

29. Yagci Y, Tasdelen MA, Jockusch S. Reduction of Cu(II) by photochemically generated phosphonyl radicals to generate $\mathrm{Cu}(\mathrm{I})$ as catalyst for atom transfer radical polymerization and azide-alkyne cycloaddition click reactions. Polymer. 2014;55(16):3468-74. 